\title{
Comment on the Manuscript "Treatment of Intermediate-Stage Hepatocellular Carcinoma in Japan: Position of Curative Therapies"
}

\author{
Zhaonan Li Dechao Jiao Xinwei Han \\ Department of Interventional Radiology, The First Affiliated Hospital of Zhengzhou University, Zhengzhou, China
}

Dear Editor,

I read with interest the study by Kariyama et al. [1]. The author retrospectively analyzed the actually conducted treatment methods and efficacy of intermediate-stage (IM) hepatocellular carcinoma (HCC) to clarify the treatment strategies suitable for IM-HCC. After analyzing the efficacy of each therapy through the Cox proportional hazard model and propensity score matching analysis, it is pointed out that radiofrequency ablation and surgical resection were effective for IM-HCC, especially in BCLCB1/B2 cases.

First of all, we congratulate the authors for the perfect match in this research. The author used 7 matching factors (age, sex, Child-Pugh score, tumor number, tumor size, AFP, and DCP), and 89 cases each were selected from $351 \mathrm{TACE}$ and 108 radiofrequency ablation. However, the precision of the PSM analysis was not mentioned. In addition, the author pointed out the deficiencies at the end of the article, including not using tyrosine kinase inhibitors and not considering PD-1 antibodies. But after the TACE of IM-HCC patients, does the patient use sorafenib to cooperate with the treatment process? Currently, sorafenib has been shown to improve time to

\begin{tabular}{ll}
\hline karger@karger.com & (c) 2021 The Author(s) \\
www.karger.com/lic & Published by S. Karger AG, Basel \\
& This article is licensed under the Creative Commons Attribution- \\
Karger & Non-NDmercial-NoDerivatives 4.0 International License (CC BY- \\
NC-NDttp://www.karger.com/Services/OpenAccessLicense). & Usage and distribution for commercial purposes as well as any dis- \\
tribution of modified material requires written permission.
\end{tabular}

progression as well as overall survival, especially when used in combination with TACE $[2,3]$. If the researcher fails to document the effects of sorafenib in the cohort study and does not consider this important adjuvant therapy, the comparison of results between the 2 groups will become meaningless.

In conclusion, we appreciate the authors' efforts in exploration of the treatment with IM-HCC. However, we suggest that appropriate modification would further confirm and greatly solidify the conclusions of the study.

\section{Statement of Ethics}

The present study protocol was approved by the Institutional Ethics Committee of the First Affiliated Hospital of Zhengzhou University.

\section{Funding Sourcess}

The authors received no financial support to produce this manuscript. 


\section{Conflict of Interest Statement}

References

The authors declare no conflicts of interest that pertain to this work.

\section{Author Contributions}

Guarantor of the article: Xinwei Han. Specific author contributions: Zhaonan Li, Dechao Jiao, and Xinwei Han designed the study and wrote the paper. All authors approved the final version of the manuscript.
1 Kariyama K, Nouso K, Wakuta A, Oonishi A, Toyoda H, Tada T, et al. Treatment of intermediate-stage hepatocellular Carcinoma in Japan: position of curative therapies. Liver Cancer. 2020 Jan 1;9(1):41-9.

2 Jin PP, Shao SY, Wu WT, Zhao XY, Huang $\mathrm{BF}, \mathrm{Fu} \mathrm{QH}$, et al. Combination of transarterial chemoembolization and sorafenib improves outcomes of unresectable hepatocellular carcinoma: an updated systematic review and meta-analysis. Jpn J Clin Oncol. 2018 Dec 1;48(12):1058-69.

3 Kudo M, Ueshima K, Ikeda M, Torimura T, Tanabe N, Aikata H, et al. Randomised, multicentre prospective trial of transarterial chemoembolisation (TACE) plus sorafenib as compared with TACE alone in patients with hepatocellular carcinoma: TACTICS trial. Gut. 2020 Aug 1;69(8):1492-501. 